\title{
A Structured Review of Information Visualization Success Measurement
}

\author{
Nadine Amende \\ University of Passau, Innstrasse 43 \\ 94032 Passau 0049-851-5092593 \\ Nadine.Amende@uni-passau.de
}

\begin{abstract}
Information visualization research has been popular for nearly two decades, but a more widespread adaption of visualization tools is missing. We present a state-of-the-art in measuring information visualization success by means of a structured literature review and a classification framework. This article identifies and classifies $\mathbf{3 0}$ empirical journal papers, and consolidates the empirical findings. The review shows an absence of theoretical success models and influence factors as a basis for indepth success analysis. Dominant research design is that of laboratory experiments which analyze an individual perspective on success. The review results are discussed and a research agenda is proposed.
\end{abstract}

Information Visualization, Information Systems Success, Success Measurement, Literature Review

\section{INTRODUCTION}

As the information visualization discipline evolves, many information visualization techniques and systems exist, but a more widespread adoption is lacking. The first hype was followed by disillusion. On the one hand, organizations want to see a payoff for their investments in any information systems (IS), but standardized instruments for measuring information visualization performance comprehensively are missing. On the other hand, many users are still struggling to use even simple visualizations [22]. Thus, it is crucial to analyze the performance of information visualization and to understand its critical influence factors. At this, the human factor plays the most important role. There is a need to analyze how information visualization supports individuals in their information tasks and how they conduct this information related tasks, e.g. how they interact with information, how they perceive it visually, how they search for information and solve problems [4] [14].

Therefore, it is important to undertake validated research and present evident results in performance or rather success measurement, which has been a permanent topic in IS research.

The aim of this paper is to analyze and describe the current state of information visualization success measurement by means of scientific methods to ensure validity. The following questions are addressed:

- Which theoretical models or frameworks for assessing success can be found in literature and were used in past empirical studies?

- Which influence factors were analyzed in past empirical studies?
- What information visualization techniques were analyzed in past empirical studies?

-Which research designs were used in past empirical studies?

To answer these questions we conducted a structured literature review. The results of this review can show first starting points to understand the lacking adoption. The remainder of this paper is structured as follows. Below, we give an overview of IS measurement in general and information visualization measurement. We then introduce our structured literature review method and present the results. Finally, we deduce a research agenda and point out some limitations of our research.

\section{INFORMATION VISUALIZATION SUCCESS MEASUREMENT}

Measuring IS success has been popular for 25 years and is an ongoing issue in IS research with a plethora of success definitions, e.g. individual or organizational performance, user acceptance or user satisfaction, and of models like the technology acceptance model by Davis [8], the task technology fit model by Goodhue [15], Roger's diffusion of innovations theory [24] or the most famous DeLone and McLean IS success model (updated 2003) [10]. Many researchers extended the established model with more dimensions and relationships, respecified them, examined the relationships or identified standardized measures to evaluate the specified dimensions. This has helped to better understand IS success [21]. In the field of information visualization Cognitive Fit Theory by Vessey [26] explains higher task performance by a match of visual representation 
of a task and decision maker's mental representation of a task.

Current evaluation practices of information visualization are experiments, case studies and technical usability studies [14]. To gain a better insight in these evaluation practices, adaption of IS success measurement expertise to the information visualization domain can be useful. Common IS success models evaluate influence factors and causal relationships in-depth. As information visualization systems are particular information systems, appliance of common IS success models is a beginning for theoretical based success measurement analysis. These models consider analyzed and validated causal relationships and important influence factors, which are a good prerequisite for analysis. Beyond, IS success measurement research defines different units and perspectives of measurement (see 3.2.1).

\section{RESEARCH METHODOLOGY}

To follow the rigor and relevance debate in IS research [18] on the one hand and a call of Webster and Watson (2002) on the other hand [27], this paper describes a structured literature research method and thus a rigorous foundation for a research agenda in information visualization success measurement.

\subsection{Structured Literature Review}

A structured literature review facilitates theory development, closes areas where plenty research exists and discovers new research areas [27]. It summarizes and integrates prior research and elicits inconsistencies, relations and gaps in research to help following a research objective.

Conducting a literature search in the IS domain is very complex and time consuming. This is caused by a constantly increasing number of IS journals and conferences, e.g. 693 active IS journals are listed in index of Information Systems Journals. ${ }^{1}$ Therefore, a relatively comprehensive number of relevant and qualitative articles is crucial for an evident literature analysis. A structured literature review ensures that all relevant sources can be gathered and analyzed by means of a scientific method [12]. The process of review and the exclusion of sources are documented. Because of this transparency and reliability of research, results of these activities can be understood and reused.

$1 \quad$ URL: http://lamp.infosys.deakin.edu.au/ journals/ last access: 08.03.2010

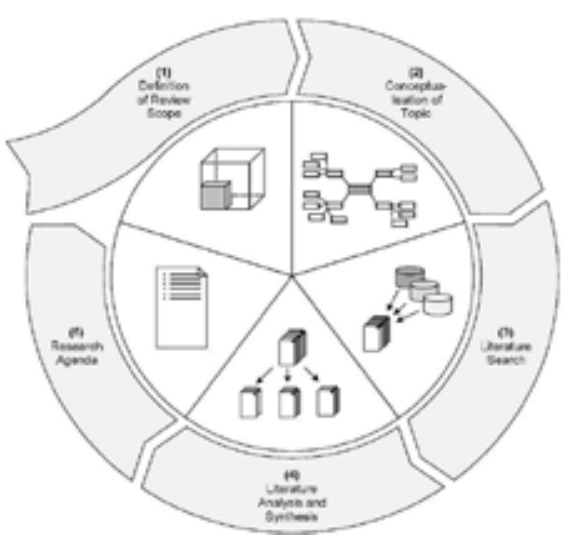

Figure 1: Process of structured literature review [2]

Brocke and Riemer recommend a 5-phasing iterative literature review process (see figure 1), which is the basis for this paper and is described below. A review process has to be iterative, because knowledge continuously grows and review results have to be updated and extended regularly [2].

\subsubsection{Definition of Review Scope}

The review scope defines the degree of coverage of sources and the period covered. The degree of coverage of sources is crucial for reviewing. Cooper distinguishes between an exhaustive review, an exhaustive review describing only a sample, a representative review typifying larger groups of articles and a pivotal review illustrating central articles [6]. In keeping with this paper's objective the state of the art of success measurement in information visualization was accomplished by means of an exhaustive review.

The period covered can be restricted as well. A period can be selective, exhaustive or determines an interval. The spread of information visualization as an area of research began with some developments at XEROX Palo Alto Research Center in the early 90's and first information visualization conferences in 1995. IS success measurement has been pushed since 1992 when DeLone and McLean published their IS success measurement model. Thus, an appropriate interval between 1992 and 2009 was determined to focus on a wide range on relevant publications.

\subsubsection{Literature Search}

A systematic selection of appropriate sources was carried out by means of is journal rankings. Multiple ranking lists [1], [13], [28], [17] and [19] were consolidated to identify top IS journals. Thus, identified top journals do not represent the perception of one researcher and one ranking method. Journals were selected, if they were listed in three out of the five ranking lists. In total, 13 top IS journals were identified. Several specific information visualization journals were added to receive more relevant articles despite a lower quality than top journals [28]. 
The selection of conference papers was rejected because of a restricted length and thus relatively unspecific statements and a lower quality than journals [2]. Books were rejected as well because of partially lacking review processes.

In a next step, appropriate key phrases were generated by combining keywords for information visualization, e.g. "map visualization", "tree visualization" with keywords for measurement, e.g. "evaluation", "benefit" or "acceptance". These key phrases were used for literature searches of electronic databases, e.g. ScienceDirect, ProQuest, Emerald, Springer and Wiley Science or journal websites. A precise key phrase excludes not necessarily relevant articles. Table 1 displays the applied searching functionalities and the used databases and websites.

\begin{tabular}{|c|c|c|c|c|}
\hline Journal & $\begin{array}{l}\text { Title } \\
\text { search }\end{array}$ & $\begin{array}{l}\text { Abstract } \\
\text { search }\end{array}$ & $\begin{array}{l}\text { Search in } \\
\text { denoted } \\
\text { article } \\
\text { keywords }\end{array}$ & $\begin{array}{l}\text { Full text } \\
\text { search }\end{array}$ \\
\hline \multicolumn{5}{|l|}{ TOP IS Journals } \\
\hline \begin{tabular}{|l|}
$\begin{array}{l}\text { Management } \\
\text { Information Systems } \\
\text { Quarterly }\end{array}$ \\
\end{tabular} & $x$ & $x$ & & $x$ \\
\hline $\begin{array}{l}\text { Information Systems } \\
\text { Research }\end{array}$ & $x$ & $x$ & $x$ & \\
\hline $\begin{array}{l}\text { Journal of } \\
\text { Management } \\
\text { information Systems }\end{array}$ & $x$ & $x$ & $x$ & \\
\hline \begin{tabular}{|l|} 
Decision Support \\
Systems
\end{tabular} & $x$ & $x$ & $x$ & \\
\hline $\begin{array}{l}\text { The DATABASE } \\
\text { for Advances in } \\
\text { lnformation Systems }\end{array}$ & $x$ & $x$ & $x$ & \\
\hline \begin{tabular}{|l} 
Information \& \\
Management
\end{tabular} & $x$ & $x$ & $x$ & \\
\hline \begin{tabular}{|l|} 
Information Systems \\
Journal
\end{tabular} & $x$ & $x$ & $x$ & $x$ \\
\hline \begin{tabular}{|l|} 
Journal of Strategic \\
Information Systems
\end{tabular} & $x$ & $x$ & $x$ & \\
\hline Management Science & $x$ & $x$ & $x$ & \\
\hline \begin{tabular}{|l|} 
Decision Science \\
\end{tabular} & $x$ & $x$ & $x$ & $x$ \\
\hline \begin{tabular}{|l|} 
European Journal of \\
Information Systems
\end{tabular} & $x$ & $x$ & $x$ & \\
\hline \begin{tabular}{|l|} 
Journal of the \\
Association for \\
Information Systems
\end{tabular} & $x$ & $x$ & $x$ & \\
\hline \begin{tabular}{|l|} 
Journal of Information \\
Technology \\
\end{tabular} & $x$ & $x$ & $x$ & \\
\hline \multicolumn{5}{|c|}{ Specific Information Visualization Journals } \\
\hline \begin{tabular}{|l|} 
Computer-Aided \\
Design
\end{tabular} & $x$ & $x$ & $x$ & \\
\hline Computers \& Graphics & $x$ & $x$ & $x$ & \\
\hline \begin{tabular}{|l|} 
Computer Graphics \\
Forum
\end{tabular} & $x$ & $x$ & $x$ & \\
\hline \begin{tabular}{|l|} 
Computer Vision and \\
Image Understanding \\
\end{tabular} & $x$ & $x$ & $x$ & \\
\hline \begin{tabular}{|l|} 
Information \\
Visualization \\
\end{tabular} & $x$ & $x$ & $x$ & \\
\hline $\begin{array}{l}\text { International Journal } \\
\text { of Human-Computer } \\
\text { Studies }\end{array}$ & $x$ & $x$ & $x$ & \\
\hline $\begin{array}{l}\text { Journal of Visual } \\
\text { Languages \& } \\
\text { Computing }\end{array}$ & $x$ & $x$ & $x$ & \\
\hline \begin{tabular}{|l|}
$\begin{array}{l}\text { Journal on Multimodal } \\
\text { User Interfaces }\end{array}$ \\
\end{tabular} & $x$ & $x$ & & $x$ \\
\hline
\end{tabular}

Table 1: Considered journals for literature review

The search of databases was conducted in three steps. Initially, articles were retrieved by searching in titles, abstracts, denoted article keywords and partially in full text. Results of this first step were 343 "initial hits".

In a second step, abstracts of these initial hits were analyzed in-depth in respect of their relevance that is, consistency with the defined time period and review objectives - use of information visualization and its success measurement. Finally, a roughly full text analysis of the 142 "abstract hits" was conducted to select relevant literature for inclusion in the review. Articles were rejected for the following reasons to ensure a certain quality of articles:

- address no empirical investigation, e.g. only meta analysis, literature review or analytical evaluation [25],

- address scientific visualization of physical data, e.g. ozone concentration in the atmosphere, instead of information visualization of non-physical data, e.g. financial and business data [3],

- do not describe research design,

- do not define a success construct, exogenous and endogenous variables for measurement,

- is a duplicate [21] or

- uses data from another source (second hand).

The evaluation phases (step 2 and 3 ) limit the amount of literature to relevant articles. The resulting list of "relevant hits" contains 30 articles, which became the basis for the literature review. Table 2 displays the results of literature search.

\begin{tabular}{|c|c|c|c|}
\hline Journal & Hits initial & Hits abstract & $\begin{array}{l}\begin{array}{l}\text { Hits full text } \\
\text { (relevant) }\end{array} \\
\text { rela }\end{array}$ \\
\hline \multicolumn{4}{|l|}{ TOP IS Journals } \\
\hline $\begin{array}{l}\text { Management Information } \\
\text { Systems Quarterly }\end{array}$ & 3 & 2 & 1 \\
\hline $\begin{array}{l}\text { Information Systems } \\
\text { Research }\end{array}$ & 0 & 0 & 0 \\
\hline \begin{tabular}{|l} 
Journal of Management \\
Information Systems \\
\end{tabular} & 8 & 5 & 0 \\
\hline Decision Support Systems & 36 & 19 & 8 \\
\hline $\begin{array}{l}\text { The DATABASE for Advances } \\
\text { in Information Systems }\end{array}$ & 21 & 3 & 0 \\
\hline Information \& Management & 8 & 2 & 1 \\
\hline Information Systems Journal & 2 & 0 & 0 \\
\hline \begin{tabular}{|l|} 
Journal of Strategic \\
Information Systems \\
\end{tabular} & 1 & 0 & 0 \\
\hline Management Science & 0 & 0 & 0 \\
\hline Decision Science & 4 & 2 & 1 \\
\hline \begin{tabular}{|l|} 
European Journal of \\
Information Systems
\end{tabular} & 9 & 0 & 0 \\
\hline $\begin{array}{l}\text { Journal of the Association for } \\
\text { Information Systems }\end{array}$ & 2 & 0 & 0 \\
\hline $\begin{array}{l}\text { Journal of Information } \\
\text { Technology }\end{array}$ & 2 & 0 & 0 \\
\hline \multicolumn{4}{|c|}{ Specific Information Visualization Journals } \\
\hline Computer-Aided Design & 3 & 0 & 0 \\
\hline Computers \& Graphics & 46 & 15 & 0 \\
\hline Computer Graphics Forum & 36 & 7 & 0 \\
\hline $\begin{array}{l}\text { Computer Vision and Image } \\
\text { Understanding }\end{array}$ & 2 & 0 & 0 \\
\hline Information Visualization & 65 & 42 & 7 \\
\hline \begin{tabular}{|l|} 
International Journal of \\
Human-Computer Studies
\end{tabular} & 44 & 20 & 9 \\
\hline $\begin{array}{l}\text { Journal of Visual Languages } \\
\text { \& Computing }\end{array}$ & 39 & 25 & 3 \\
\hline $\begin{array}{l}\text { Journal on Multimodal User } \\
\text { Interfaces }\end{array}$ & 12 & 0 & 0 \\
\hline$\sum$ & 343 & 142 & 30 \\
\hline
\end{tabular}

Table 2: Results of literature search

\subsection{Literature Analysis and Synthesis}

The identified relevant articles were considered for an in-depth analysis and synthesis. For evident results the analysis and synthesis process has to be conducted systematically. A framework was 
developed to categorize the relevant articles and to structure the analysis process.

\subsubsection{Framework for Analyzing Literature}

Several authors recommend a framework for arranging, discussing and synthesizing prior research. Hart and Webster/Watson provide a generic Framework with generic categories for any research discipline [16, 48ff] [27]. A framework considering specifics of IS success measurement was defined by DeLone and McLean [9], Petter et al. [21] and Urbach et al. [25]. This preliminary work was adapted and amended to analyze and synthesize information visualization success measurement systematically. The developed framework consists of 10 categories displayed in table 3 .

\begin{tabular}{|l|l|}
\hline Categories & Values \\
\hline $\begin{array}{l}\text { Theoretical success } \\
\text { model }\end{array}$ & $\begin{array}{l}\text { D\&M, TAM, TTF, EUCS, Diffusion of } \\
\text { innovations, SERVQUAL, Cognitive Fit, } \\
\text { Other, n/a }\end{array}$ \\
\hline Endogenous variables & $\begin{array}{l}\text { Effectiveness, Efficiency, Satisfaction, } \\
\text { Usefulness, Ease of Use, Preference, } \\
\text { Enjoyment, Comfort, Other }\end{array}$ \\
\hline Exogenous variables & $\begin{array}{l}\text { Visualization type, Task complexity, Task } \\
\text { type, User skills, System quality, Other }\end{array}$ \\
\hline Operationalization & $\begin{array}{l}\text { Time measurement, Task correctness, } \\
\text { Rating scale, Preference ranking order, } \\
\text { Other }\end{array}$ \\
\hline Research object - & $\begin{array}{l}\text { Tree, Network, Conceptual map, Spatial } \\
\text { map, Fisheye View, Diagram, Matrix, } \\
\text { Virtual environment, Perspective Wall, } \\
\text { TileBar, Other }\end{array}$ \\
\hline Visualization type & $\begin{array}{l}\text { Visualization of search results, } \\
\text { Navigation in information space, } \\
\text { Represent reality, Problem solving, } \\
\text { Analysis and pattern recognition, Other }\end{array}$ \\
\hline Objective of \\
visualization & Individual, Group, Organisation \\
\hline Research unit & $\begin{array}{l}\text { Internal User, IS personnel, IS } \\
\text { executives, External stakeholder } \\
\text { (customers, suppliers), Multi stakeholder }\end{array}$ \\
\hline \multirow{2}{*}{ Evata analysis } & $\begin{array}{l}\text { Survey, Case study, Experiment, } \\
\text { Interview, Observation, Other }\end{array}$ \\
\hline Research strategy & $\begin{array}{l}\text { Structural equation modeling, } \\
\text { Regression analysis, Factor analysis, } \\
\text { Variance analysis, Cluster analysis, } \\
\text { t-Test, Other }\end{array}$ \\
\hline &
\end{tabular}

Table 3: Literature analysis framework

Theoretical foundations for IS success measurement were determined to analyze their use for information visualization evaluation. Therefore, common IS success reference models and frameworks e.g. the updated D\&M model, TAM, TTF, diffusion of innovations theory, End User Computing Satisfaction - EUCS by Doll and Torkzadeh [11] and SERVQUAL by Parasuraman et al. [20] were considered [21]. The cognitive fit model emerged from information visualization research was added. Articles which referenced another theory were categorized as "other" or which referenced no theory were categorized as "n/a" (not applicable).

Endogenous and exogenous variables were determined to analyze the underlying success constructs in-depth. That is, it is crucial to know and analyze potential factors which can influence success and to clearly define success. Endogenous variables were deduced from theoretical success models.
Exogenous variables describe influence factors for successful visualization and were deduced from IS success models and information visualization theory [22]. Articles which used no designated variables were categorized as "other".

The two categories visualization type and objective of visualization were determined to present the object of analysis and show the focus of the investigated studies. Common visualization types: tree, network, conceptual map, spatial map, fisheye view, matrix, diagram, tilebar, perspective wall and virtual environment visualization were identified [23] [3] [5]. Other possible visualization types were categorized as "other". The objective of visualization is to visualize search results, support navigation in information space, support pattern regcognition, represent reality and support problem solving [23] [3] [7] [8].

A success measurement can be conducted on different organizational levels meaning the unit of observation. Success can be measured as individual, group or as organizational benefit. Measuring an organizational benefit is often difficult because of the numerous influence factors which do not allow tracing success back to solely an information visualization system. Thus, an individual perspective is auxiliary, because an individual has to work with the information visualization system. Explicit conclusions can be drawn more easily [16] [27].

The evaluation perspective category defines different perspectives on success e.g. internal user, IS personnel, IS executives, customers and suppliers (external stakeholders) or multistakeholders. Because of different interests in evaluating IS, different users can generate different success measurement results. Considering different user perspectives is crucial for a comprehensive understanding of information visualization success [25].

Research strategy category describes the used methodology to gather data. Common empirical IS methodologies are survey, case study, experiment, interview and observation. The category data analysis refers to frequently used techniques e.g. structural equation modeling, regression analysis, factor analysis, variance analysis, cluster analysis and t-test [25]. Both categories permit to analyze reliability, internal and external validity of the empirical studies.

\section{RESEARCH AGENDA}

The results (see figure $2 a$ and $2 b$ ) show that use of theoretical consolidated success models is weak. Only 2 studies used cognitive fit theory and 1 the task technology fit model as foundation. The use of theoretical models can improve analyzing success 
and its influence factors. These models permit a structured and holistic analysis of influence factors and causal relationships. They depict already investigated and validated influence factors and causal relationships. Due to their popularity, many studies exist presenting measures and approaches for evaluation. Measures of these common success models can be adapted for information visualization research.

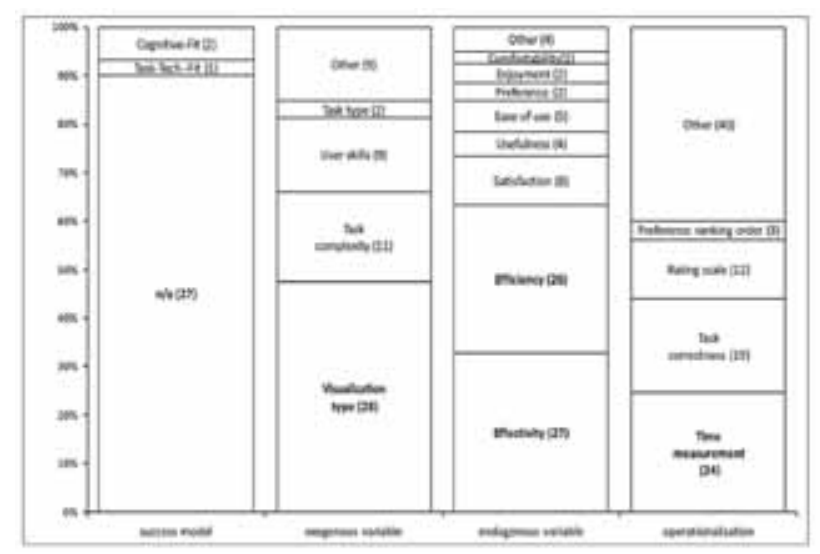

Figure 2: Classification of relevant literature 1

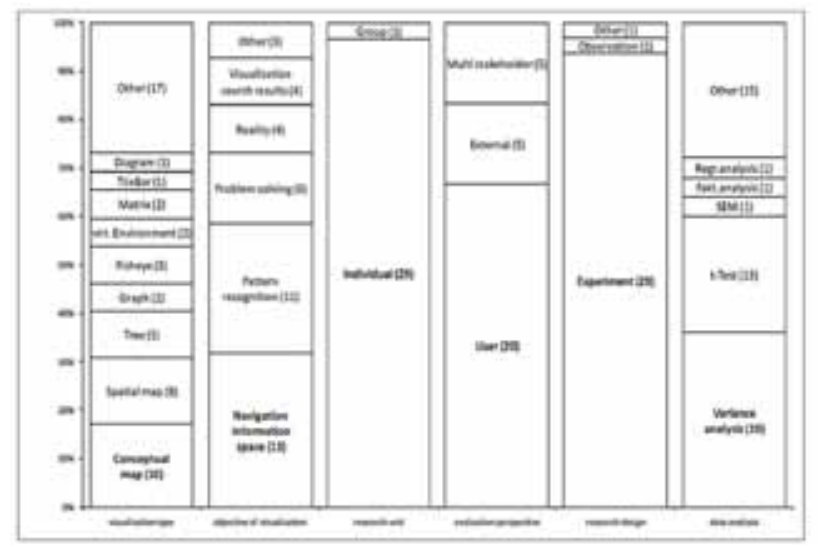

Figure 3: Classification of relevant literature 2

Thus, validated success models support a rigor evaluation process. There has to be more research by applying common success models and adapting IS models for the domain of information visualization or developing new models.

A more in-depth analysis of influence factors reveals that most studies only analyze influences by varying visualization types (28) and additionally task complexities (11). Exogenous variables like user skills, task type, system quality and other constructs contained in success models like performance expectation, voluntariness, subjective norm has to be investigated for deeper understanding of success. Most used endogenous variables are effectiveness (27) and efficiency (26) measured by task correctness and time. These have to be amended by other success constructs like satisfaction, acceptance or use of information visualization to gain better insight. Conceptual maps (10) and spatial maps (8) are frequently analyzed. To provide evident and useful information visualization systems for diverse tasks the remaining visualization techniques has to be investigated as well.

Dominant research perspective is the individual (29) user (20) perspective, which results from usercentered information visualization design strategy. A holistic understanding of information visualization success is missing. For a holistic understanding other research units and perspectives has to be considered. Success measurement has to take place also at the organizational level e. g. organizational benefits, to show a return on investment. Different perspectives have to be involved e. g. Stakeholders. This multidimensional success definition could be a source of information visualization adoption. However, measuring organizational benefit is hard. There are many factors (e. g. market situation), which can influence organizational benefit, so that it is difficult to infer visualization systems influence exclusively. At the moment, there is no possibility how this difficulty could be dealt with. This is also claimed in other research domains like knowledge or information management.

Most common research design is laboratory experiment (29) and variance analysis (19) or simple t-test (13). This has been mentioned earlier by Plaisant who called for alternative designs e.g. case studies, action research and ethnographic studies to support more in-depth analysis and evident research results as well [22]. Beyond, instead of laboratory artificial settings research has to be down in reallife settings with real datasets and realistic tasks to ensure generalizability.

\section{CONCLUSIONS}

Information visualization research has been popular for nearly two decades, but a broad adoption of systems is missing. We presented a state-of-theart in measuring information visualization success by means of a scientific method and pinpoint future research. Limitations of the structured literature review can be seen in the definition of review scope, the selection of relevant journals and key phrases, the rejection of conference articles and omitted backward and forward search in article references. This could have elided potentially relevant articles. The literature review was conducted by one person. Thus, subjective interpretations could result, but can be avoided by intercoder reliability tests.

Success measurement is important for researchers and for practitioners to see a return on their investments. This literature review presented starting points for understanding the lacking adoption of information visualization systems. Future information visualization success research has to concentrate on holistic or rather multidimensional and in-depth analysis of success. Concerning the 
first, different stakeholder perspectives have to be analyzed. Concerning the last, there has to be more investigation of various influence factors and causal relationships. This can be assured by means of theoretic IS success models. From a practical perspective there has to be an analysis of costs as influence factor too. In-depth analysis can be ensured by analyzing real human behavior in realistic experiment settings and by using qualitative research design strategies e. g. action research, case studies or ethnographic studies.

\section{ACKNOWLEDGMENTS}

Thanks to colleagues and reviewers for many fruitful discussions and valuable comments.

\section{REFERENCES}

1. Association for Information Systems 2006. $U R L=$ http://ais.affiniscape.com/displaycommon. $\mathrm{cfm}$ ?an=1\&subarticlenbr $=432$.

2. vom Brocke, J., Simons, A., Niehaves, B., Riemer, K., Plattfaut, R. and Cleven, A. 2009. Reconstructing the Giant: On the Importance of Rigour in Documenting the Literature Search Process, In Proceedings of the 17th European Conference on Information Systems (ECIS) (Verona, Italy, June 08-10, 2009).

3. Card, S., Mackinlay, J. and Shneiderman, B. 1999. Readings in Information Visualization: Using Vision to Think, Morgan Kaufmann.

4. Carpendale, S. 2008. Evaluating Information Visualizations, In Information Visualization, Kerren, A., Stasko, J.T., Fekete, J.-D. and North, C., Eds LNCS 4950, 19-45.

5. Chen, C. 2004. Information Visualization, 2nd Springer, London.

6. Cooper, H. M. 1988. "Organizing Knowledge syntheses: A taxonomy of literature reviews", Knowledge in Society, Vol. 1, 104-126.

7. Däßler, R. 1999. Informationsvisualisierung Stand, Kritik und Perspektiven, Research Paper, Projekt Group Infoviz, UAS Potsdam.

8. Davis, F. D. 1986. A technology acceptance model for empirical testing new end-user information systems: Theory and results, Doctoral dissertation, Sloan School of Management, Massachusetts Institute of Technology.

9. DeLone, W. H. and McLean, E. R. 1992. "Information Systems Success: The Quest for the Dependent Variable", Information Systems Research, Vol. 3, No. 1, 60-95. DOI= 10.1287/ isre.3.1.60
10. DeLone, W. H. and McLean, E. R. 2003. "The DeLone and McLean Model of Information Systems Success: A Ten-Year Update", Journal of Management Information Systems, Vol. 19, No. 4, 9-30.

11. Doll, W. J. and Torkzadeh, G. 1988. The measurement of end-user computing satisfaction, MIS Quarterly, Vol.12, No. 2, 259-274.

12. Fettke, P. 2006. "State-of-the-Art des State-ofthe-Art: Eine Untersuchung der Forschungsmethode "Review" innerhalb der Wirtschaftsinformatik", WIRTSCHAFTSINFORMATIK, Vol. 48, No. 4, 257266. DOI=10.1007/s11576-009-0181-y

13. Fisher, J., Shanks, G. and Lamp, J. 2007. "A Ranking List for Information Systems Journals", Australasian Journal of Information Systems, Vol. 14 , No. 1, 5-18.

14. Gershon, N., Eick, S. G. and Card, S. 1998. "Information Visualization", Interactions, Vol. 5, No. 2, 9-15. DOI= http://doi.acm. org/10.1145/274430.274432

15. Goodhue, D. L. 1995. "Understanding user evaluations of information systems", Management Science, Vol. 41, No. 12, 1827-1844. DOI=10.1287/ mnsc. 41.12.1827

16. Hart, C. 1998. Doing a literature review: releasing the social science research imagination, Sage Publications, London.

17. Hennig-Thurau, T., Walsh, G. and Schrader, U. 2004. „VHB-JOURQUAL: Ein Ranking von betriebswirtschaftlich relevanten Zeitschriften auf der Grundlage von Experten-urteilen“, Zeitschrift für betriebswirtschaftliche Forschung, Vol. 56, No. 1, 520-545.

18. Hevner, A. R., March, S. T., Park, J. and Ram, S. 2004. "Design science in Information Systems research", MIS Quarterly, Vol. 28, No. 1, 75-105. DOI $=10.1007 / \mathrm{s} 11576-006-0028-8$

19. Holsapple,C.W.2009."ANew Map forKnowledge Dissemination Channels", Communications of the ACM, Vol. 52, No. 3, 117-125. DOI= http://doi.acm. org/10.1145/1467247.1467276

20. Parasuraman, A., Berry, L. L. and Zeithaml, V. A. 1988. "A Conceptual Model of Service Quality and Its Implications for Future Research", Journal of Marketing, Vol. 49, No. 4, 41-50.

21. Petter, S., DeLone, W. and McLean, E. 2008. "Measuring Information Systems Success: Models, Dimensions, Measures, and Relationships", European Journal of Information Systems, Vol. 17, No. 3, 236-263. DOI= 10.1057/ejis.2008.15

22. Plaisant, C. 2004. The Challenge of Information Visualization Evaluation, In Proceedings of the working Conference on Advanced visual interfaces (Gallipoli, Italy, May 25-28, 2004). DOI= http://doi. acm.org/10.1145/989863.989880 
23. Plaisant, C. 2005. Information Visualization and the Challenge of Universal Usability, In Exploring Geovisualization, Dykes, J., MacEachren, A. and Kraak, M. J., Eds., Elsevier, 53-82, Oxford.

Rogers, E. M. 1995. Diffusions of Innovations, 4th, Free Press, New York.

24. Urbach, N., Smolnik, S. and Riempp, G. 2008. A Methodological Examination of Empirical Research on Information Systems Success: 2003 to 2007, In Proceedings of the 14th Americas Conference on Information Systems (AMCIS) (Toronto, ON, Canada, August 14-17, 2008). DOI= 10.1007/s12599-0090059-y

25. Vessey, I. 1991. "Cognitive Fit: A Theory-Based Analysis of the Graph Versus Table Literature", Decision Sciences, Vol. 22, No. 2, 219-240. DOI= 10.1111/j.1540-5915.1991.tb00344.x

26. Webster, J. and Watson, R. T. 2002. "Analyzing the Past to Prepare for the Future: Writing a Literature Review", MIS Quarterly, Vol. 26, No. 2, xiii-xxiii.

27. Willcocks, L, Whitley, E. A. and Avgerou, C. 2008. "The Ranking of top IS journals: a Perspective from the London School of Economics", European Journal of Information Systems, Vol. 17, 163-168. DOI $=10.1057 /$ ejis. 